\title{
Atenção em Fisioterapia no Sistema Municipal de Saúde de Botucatu (Sp): a Visão de Profissionais de Saúde da Família.
}

\author{
Zarili, Thais Fernanda Tortorelli; Dias, Maria Dionísia do Amaral \\ Universidade Estadual Paulista "Julio de Mesquita Filho" — thaiszarili@gmail.com
}

INTRODUÇÃO: a sociedade convive na atualidade com o aumento da expectativa de vida e hábitos de vida prejudiciais à saúde com impactos no perfil de adoecimento das populações. no Brasil o Sistema Único de Saúde organiza-se tendo a Atenção Primária como base e a concepção de redes de atenção integral, contrapondo-se ao modelo hospitolocêntrico. Nesse contexto inicia-se a inserção do fisioterapeuta, especialmente no Núcleo de Apoio à Saúde da Família (NASF), o que exige deste profissional ações não somente em caráter reabilitador, mas também em atuação de promoção e prevenção da saúde. o presente trabalho busca contribuir para a organização e gestão em saúde, demonstrando que a qualidade da assistência depende e muito dos recursos humanos disponíveis, assim como da existência de retaguarda articulada com a Atenção Básica. OBJETIVO: Identificar a visão de profissionais de Saúde da Família com relação à contribuição que a Fisioterapia possui para o cuidado integral aos usuários. METODOLOGIA: o projeto foi aprovado pelo Comitê de Ética e Pesquisa da Faculdade de Medicina de Botucatu-Unesp. Estudo qualitativo que utilizou um questionário auto-aplicável com vinte e sete questões estruturado pelo pesquisador, aplicado aos médicos e enfermeiros das unidades de Saúde da Família do município de Botucatu - SP. Contém questões para caracterização do entrevistado, dificuldades do processo de trabalho, a visão dos profissionais quanto à contribuição da Fisioterapia na saúde nos usuários, a consolidação da equipe do NASF no município e dos serviços de retaguarda de Fisioterapia. As respostas foram analisadas e categorizadas. RESULTADOS: Os resultados demonstram que os profissionais possuem conhecimento quanto à atuação da Fisioterapia e de sua contribuição para a resolutividade e melhoria da qualidade de vida do paciente. As queixas crônicas, especialmente em relação aos quadros álgicos, consistem em grande demanda nas unidades de saúde e causam sobrecarga na rotina de atendimentos, particularmente em razão do objetivo de qualidade da assistência desses profissionais. As ações de promoção e prevenção também se destacaram nos relatos dos respondentes, percepção essa que contribui ainda mais para a interação entre a equipe da unidade de saúde e equipe do NASF. CONCLUSÃO: a Fisioterapia atua em várias vertentes do cuidado ao usuário e sua recente inserção na Atenção Básica permite um panorama de melhoria da assistência prestada, contribuindo para um sistema de saúde universal, equitativo, com a transformação do modelo de atenção, por meio das intervenções multiprofissionais, o cuidado integral e a construção e manutenção das redes de cuidado.

Zarili, Thais Fernanda Tortorelli; Dias, Maria Dionísia do Amaral. Atenção em Fisioterapia no Sistema Municipal de Saúde de Botucatu (Sp): a Visão de Profissionais de Saúde da Família.. In: Anais do Congresso Internacional de Humanidades \& Humanização em Saúde [= Blucher Medical Proceedings, num.2, vol.1]. São Paulo: Editora Blucher, 2014. ISSN 2357-7282

DOI 10.5151/medpro-cihhs-10200 